\title{
Would Enterprises Send Food Traceability Information to Consumers?
}

\author{
Wu Tianzhen ${ }^{1}$, Wang Ruimei ${ }^{1}$, Hu Hongwei ${ }^{1} \&$ Song Huan ${ }^{1}$ \\ ${ }^{1}$ College of economics and management, China Agricultural University, Beijing, China \\ Correspondence: Wu Tianzhen, College of Economics and Management, China Agricultural University, Beijing, \\ Haidian District, Qinghuadonglu NO. 17. Tel: 15201427471. E-mail: cautianzhen@cau.edu.cn
}

Received: November 2, 2014 Accepted: November 28, 2014 Online Published: December 1, 2014

doi:10.5539/jfr.v4n1p105

URL: http://dx.doi.org/10.5539/jfr.v4n1p105

\begin{abstract}
Food security incidents have enhanced Chinese consumers' concerns about food quality and security. These growing concerns have increased demand for security of food and led to development of Chinese food traceability system. Based on the literature review, this paper built a signaling dynamic game model of information delivery from enterprises to consumers to explore the refining Bayes Nash equilibrium. The analytical results show that "good" enterprise need to send enough food traceability information to get themselves separated from "bad" enterprises, while enterprises which were "not that good" had to send much more information to achieve that trust of consumers.
\end{abstract}

Keywords: signaling game, food traceability information, food security

\section{Introduction}

Currently, food security has become a global issue concerned by China and overseas countries. Each year, about $1 / 3$ of the world population have foodborne diseases and 1.5 billion are infected with diarrhea, of which $70 \%$ are directly caused by biological or chemical food contamination (Chen, 2004). As a result of industrialization of food producing and processing, the application and popularization of new raw materials, new technology and research products, and the globalization of food trade, there are a growing number of factors which may contaminate foods. New problems keep arising while the old have not been solved.

Since the 1970s, food security incidents occurred frequently all over the world. The outbreak of foodborne diseases, such as mad cow disease, foot and mouth disease, avian flu and dioxin have had a huge impact on the economic and social development of all the countries. As a result, the public are paying more attention to the issue of food security, and the government is asked to build a food traceability system as soon as possible.

The issue of food security is one of the major events bearing upon the national economy and people's livelihood. Ensuring food security became a strategic target of China. The nature of this problem is the reverse selection under information asymmetry. As an effective measure to decrease food security risks, food traceability system produces reliable and continuous flow of information on supply chain to monitor food production processes and identify various problems with quality signal transmission mechanism. In this way, the system can solve the problems of information insufficiency and asymmetry in the food market and identify the responsible bodies to ensure food security (Cui et al., 2013).

Food traceability information mentioned in this paper includes two parts of information: one part is food production information, in which information of the food ingredients, production date, batch lot, manufacturer and GM or not etc. are included; the other part is logistical information refers to its amount, condition of stockpile and transport, transit line, package, test reports etc. in food supply chain. From the view of consumers, food traceability information covers all the information generated in food supply chain including production, processing, distribution and marketing, which could be helpful to consumers to identify the security level of the food they are buying.

From the perspective of enterprises, this paper is trying to answer whether enterprises would send consumers food traceability information to achieve their trust for food. Based on signaling game theory, a dynamic game model under information asymmetry is designed to explore the theoretical explanation why enterprises would sent consumers food traceability information. The way to turn a "lemon market" into a "good" one is discussed and that will contribute the development of food traceability system in China, improve food security level, and cut economic loss of the society. 


\section{Literature Review}

Large numbers of researches have been done in area of food security management. From the perspective of economics, most scholars believe that information asymmetry is the fundamental cause of food security problems. As food security are experience and credence goods (Nelson, 1970), on the way to propose a food policy, scholars focused on the discussion of government regulation (Wu \& Zeng, 2012) and they believe information disclosure would help to control food security level (Bagwell \& Riordan, 1991; Caswell \& Mojduszka, 1996; Liu et al., 2011). In the researches of food security information delivery, scholars have discussed the condition and problems of food security information delivery in China, and explored the way to establish an effective mechanism with reference to foreign experience in information delivery.

In the area of signaling game theory, this theory was established by Spence in 1970s. Spence, owner of the Noble Economic Prize, took education as a signal to distinguish the type of workers in labor market (Spence, 1974; Spence, 2002). After that, advertisements (Nelson, 1974), capital structure (Ross, 1977), advertisements and price (Milgrom \& Roberts, 1986), medical treatment were taken as signals to discuss the gaming problem in different markets. Signaling game theory even was used to analysis problems of human resource management, customer relationship management and peacock tail spreading and so on.

In the economic researches of food security management, most scholars focused on the role of the government in information delivery, and discussed how to establish the food security information delivery mechanism on macro level, but few researches have given the micro-explanation why enterprises would like to join this information delivery mechanism, and whether they would sent consumers food traceability information voluntarily. Based on a new perspective, this paper explored the internal mechanism of information delivery, and proposed policies to cultivate a high-quality market.

\section{Modeling}

In the market, as food traceability information is enterprises' private information, and enterprises take their actions before consumers, this problem can be regarded as an incomplete information dynamic game.

\subsection{Game Process Description}

In this incomplete information signaling game, the signal sender are enterprises and receiver are consumers. Based on their private information on food, enterprises send consumers a certain amount of traceability information as a signal, and after consumers receive the signal they decide their pay price for the food. The chronological order of this signaling game model is shown as follows.

(1) Nature decides enterprises' food security type. In order to simplify the question, we assume that there are two types of enterprises' food security level: $T=\left\{t_{H}, t_{L}\right\}$, and let the probability of enterprises with a high food security level $p\left(t_{H}\right)=q$, and then the probability of enterprises with a low food security level $p\left(t_{L}\right)=1-q$.

(2) Based on the food security type of themselves, enterprises choose to send a certain amount of food traceability information $x \geq 0$.

(3) Consumers receive $x$ (not their type), and provide a pay price $P(x)$. Thus, enterprises' profit function $\pi(t, x)=$ $P(x)-c(t, x)$, of which $c(t, x)$ is the information delivery cost while enterprises with a food security type $t$ choose to send $x$ unit of food traceability information.

Consumers' utility function $u(t, x)=X(t, x)-P(x)$, of which $X(t, x)$ is consumer surplus while consumers consumed food with a food security type $t$ and information delivery amount $x$.

\subsection{Assumptions}

(1) Food traceability information delivery amount $x$ belongs to a real number interval. We assume that food traceability information is enterprises' private and real information and can't be imitated by others enterprises.

(2) Consumers would get a higher consumer surplus while consuming food with a high security level. That is, for any $x$ :

$$
X\left(t_{H}, x\right)>X\left(t_{L}, x\right)
$$

And also we assume food traceability information delivery would not decrease consumer surplus. That is, for any $x$ :

$$
\frac{\partial X(t, x)}{\partial x} \geq 0
$$


Of which, $\frac{\partial x(t, x)}{\partial x}$ represents consumers' marginal surplus.

(3) Compared with enterprises with a lower food security level, enterprises with a higher food security level would have a lower information delivery cost. That is, for any $x$ :

$$
\frac{\partial c\left(t_{H}, x\right)}{\partial x}<\frac{\partial c\left(t_{L}, x\right)}{\partial x}
$$

Of which, $\frac{\partial c(t, x)}{\partial x}$ represents enterprises' marginal information delivery cost as shown in Figure 1.

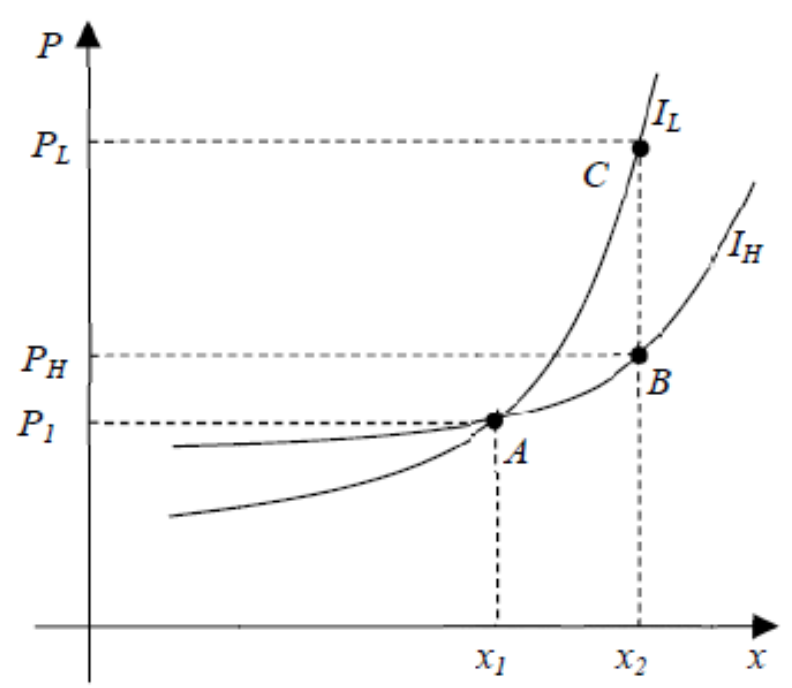

Figure 1. Enterprises' indifference curve of information delivery amount and price

(4) We assume that consumers' expected utility approaches zero. Thus, we can use one signal receiver to represent the others. For a given market, after consumers observe signal $x$, their pay price equals their expected surplus. That is:

$$
P(x)=p\left(t_{H} \mid x\right) \cdot X\left(t_{H}, x\right)+\left(1-p\left(t_{L} \mid x\right)\right) \cdot X\left(t_{L}, x\right)
$$

Of which, $p\left(t_{H} \mid x\right)$ is posterior probability.

Before we explore the refining Bayes Nash equilibrium of the game described above, let's discuss the corresponding complete information game. Namely, enterprises' food security type $t$ is common knowledge to enterprises and consumers. Under this circumstance, enterprises which have a food security type $t$ and traceability information amount $x$ would have a pay price:

$$
P(x)=X(t, x)
$$

Therefore, enterprises' optimal food traceability information delivery amount $x^{*}(t)$ :

$$
x^{*}(t) \in \arg \operatorname{Max}_{x} X(t, x)-c(t, x)
$$

Let $P^{*}(\mathrm{t})=X\left(t, x^{*}(t)\right)$, point $\mathrm{A}$ is the optimal solution for enterprises with a lower food security level, and point $B$ is the optimal solution for enterprises with a higher food security level as shown in Figure 2. 


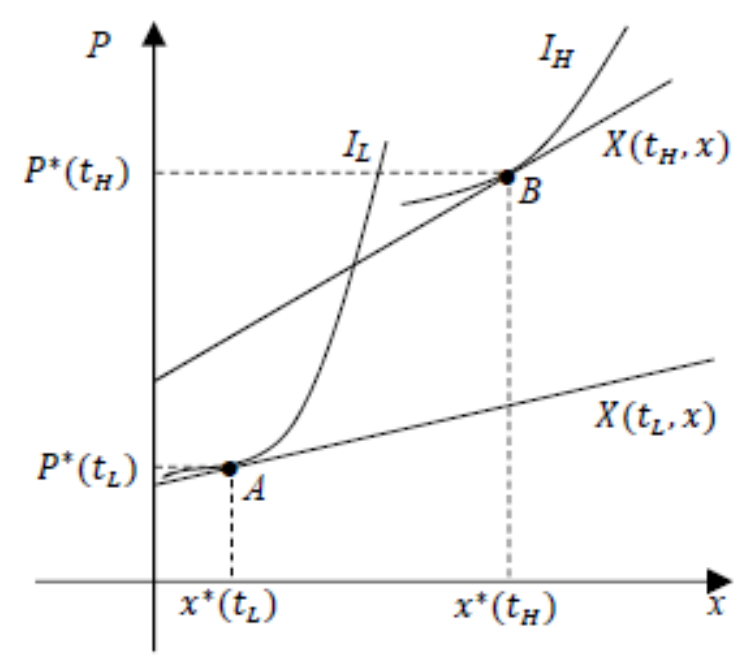

Figure 2. Equilibrium with complete information

\section{Analysis and Discussion}

\subsection{Separating Equilibrium of Food Traceability Information Delivery}

In this signaling game model, if there is a separating refining Bayes Nash equilibrium, it means enterprises with a higher food security level could get themselves separated from those with lower food security level through food traceability information delivery. Whether there exists a separating equilibrium, it depends on the forms of enterprises' indifference curve and consumer surplus function. For the given indifference and consumer surplus function shown in Figure 3, under the separating equilibrium, we assume enterprises' strategy is:

$$
x(t)= \begin{cases}x^{*}\left(t_{L}\right), & t=t_{L} \\ x^{*}\left(t_{H}\right), & t=t_{H}\end{cases}
$$

Consumers observe either of the two strategies, and their deduction is:

$$
p\left(t_{H} \mid x^{*}\left(t_{H}\right)\right)=1, p\left(t_{H} \mid x^{*}\left(t_{L}\right)\right)=0
$$

Thus, consumer' strategy is:

$$
\mathrm{P}\left(x^{*}\left(t_{L}\right)\right)=\mathrm{P}^{*}\left(t_{L}\right), \quad \mathrm{P}\left(x^{*}\left(t_{H}\right)\right)=\mathrm{P}^{*}\left(t_{H}\right)
$$

For the further discussion, we have to prove enterprises' optimal choice is $x=x^{*}(t)$ responding to consumers' strategy $P(x)$.

We assume, in the disequilibrium path consumers' deduction is:

$$
p\left(t_{H} \mid x\right)=\left\{\begin{array}{l}
0, x<x^{*}\left(t_{H}\right) \\
1, x \geq x^{*}\left(t_{H}\right)
\end{array}\right.
$$

Thus, onsumers' strategy is:

$$
P(x)=\left\{\begin{array}{l}
X\left(t_{L}, x\right), x<x^{*}\left(t_{H}\right) \\
X\left(t_{H}, x\right), x \geq x^{*}\left(t_{H}\right)
\end{array}\right.
$$

For the consumers' deduction and strategy above:

(1) Enterprises with a higher food security level would have an indifference curve located below $I_{H}$ when choosing any $x \geq x^{*}\left(t_{H}\right)$. At the same time, their indifference curve would not locate above $I_{H}^{\prime}$ when choosing any $x<x^{*}\left(t_{H}\right)$.

(2) Enterprises with a lower food security level would have an indifference curve located below $I_{L}$ when choosing any $x<x^{*}\left(t_{H}\right)\left(x \neq x^{*}\left(t_{L}\right)\right)$. At the same time, their indifference curve would not locate above $I_{L}^{\prime}$ when choosing any $x \geq x^{*}\left(t_{H}\right)$. 
Therefore, Equation 3 is enterprises' optimal responds to consumers' strategy $P(x)$.

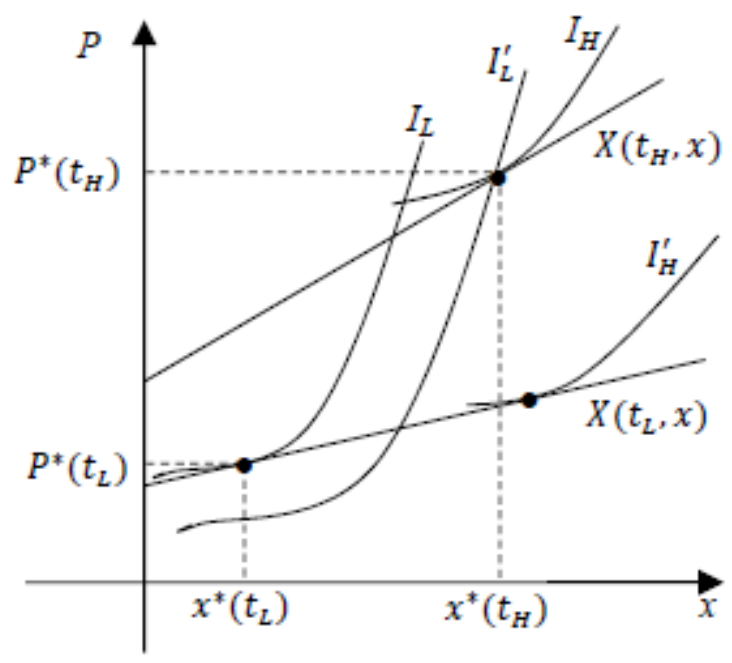

Figure 3. Separating equilibrium

In conclusion: For the given indifference curve and consumer surplus function, enterprises' strategy $\left(x\left(t_{L}\right)=\right.$ $x^{*}\left(t_{L}\right), x\left(t_{H}\right)=x^{*}\left(t_{H}\right)$ ) and consumers' deduction $p\left(t_{H} \mid x\right)$ and strategy $P(x)$ shown in Equation 2 and Equation 3 make up the separating refining Bayes Nash equilibrium of this signaling game model.

Although consumers couldn't acknowledge enterprises' real food security level, they could observe enterprises' information delivery amount. Only if enterprises sent enough information to consumers, could consumers realize the security level of enterprises' products.

\subsection{Separating Equilibrium With More Information to Send}

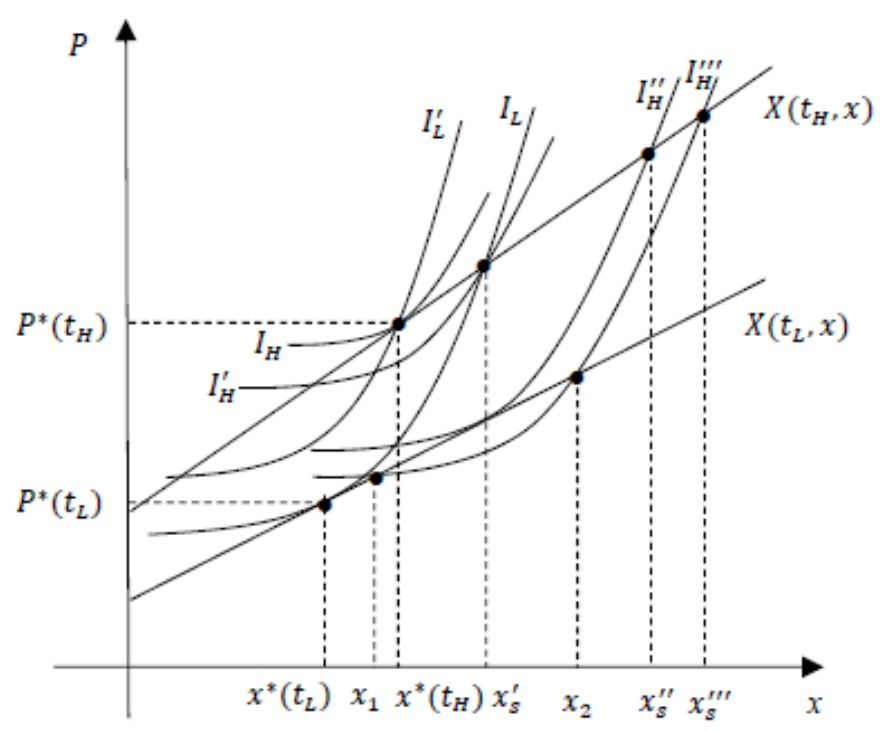

Figure 4. Separating equilibrium with more information to send

For the given indifference curve and consumer surplus function in Figure 4, the separating equilibrium we 
discussed above doesn't exist. Enterprises with a lower food security level would choose $x^{*}\left(t_{H}\right)$, not $x^{*}\left(t_{L}\right)$ responding to consumers' strategy $P(x)$ as indifference curve $I_{L}^{\prime}$ located above $I_{L}$. Under this circumstance, enterprise with a lower food security level could pretend to be higher ones by sending $x^{*}\left(t_{H}\right)$ unit of food traceability information, and this is a pooling equilibrium in signaling game.

In order to prevent enterprises with a lower food security level pretending to be higher ones, the latter have sent more food traceability information, such as $x=x_{s}^{\prime}$.

Even though enterprise with a higher food security level could sent more information to get themselves separated from lower ones, this kind of choice is limited. As shown in Figure 4, when enterprises with a higher food security level choose an information delivery amount $x_{s}^{\prime \prime \prime}$ bigger than $x_{s}^{\prime \prime}$, their indifference curve is located below $I_{H}^{\prime \prime}$. If they choose an information delivery amount belonging to interval $\left[x_{1}, x_{2}\right]$, even though they are taken as lower ones, they would have a difference curve located above $I_{H}^{\prime \prime \prime}$. In such a way, enterprises with a higher food security level would never choose an information delivery amount bigger thanx ${ }_{s}^{\prime \prime}$.

Compared with the Indifference curve $I_{H}$ in Figure 3, $I_{H}$ in Figure 4 represents a different food security level. In fact, as shown in Figure 5, when indifference curve moves along $X\left(t_{H}, x\right)$ from point $\mathrm{A}$ to $\mathrm{B}$, enterprises' food security level drops, which means enterprises with $I_{H}$ in Figure 3 have a "good" food security level while enterprises in Figure 4 are "not that good". Thus, we conclude enterprises which are "not that good" have to send much more information to achieve separating equilibrium.

\section{Conclusion}

In this paper, we built a signaling dynamic game model of information delivery from enterprises to consumers to explore the refining Byes Nash equilibrium. The analytical results show that, if enterprises want to get consumers' trust, they should send them enough food traceability information. If they don't, consumers cannot distinguish their food security type. And for enterprises which are "not that good" have to send much more information to achieve consumers' trust. For the further research, we will discuss how consumers' improved food security awareness impacts the market.

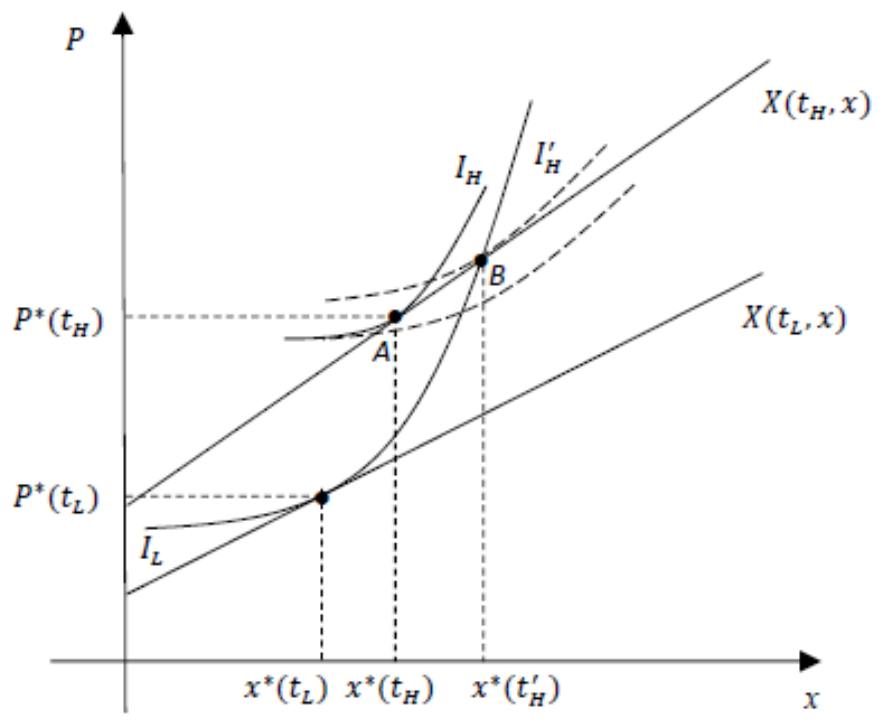

Figure 5. movement of indifference curve $I_{H}$

\section{Acknowledgements}

This paper was partially supported by National Key Technology R\&D Program of the Ministry of Science and Technology (No.2014BAL07B05), Humanities and Social Sciences Foundation of Ministry of Education of China (No.13YJCZH182) and Advance Research of China Agricultural University. Beijing, China (No.2014RW021). 


\section{References}

Bagwell, K., \& Riordan, M. H. (1991). High and Declining Prices Signal Product Quality. American Economic Review, 81(1), 224-239. http://www.jstor.org/stable/2006797

Caswell, J. A., \& Mojduszka, E. M. (1996). Using Information Labeling to Influence the Market for Quality in Food Products. American Journal of Agricultural Economics, 78(5), 1248-1253. http://dx.doi.org/10.2307/1243501

Chen, X. W., \& Deng, N. (2004). Food security strategy of China. Beijing: Chemical Industry Press.

Cui, C., Wang, K., \& Zou, S. (2013). Review of Traceability System of Food Safety. World Agriculture, 5, 27-32.

Liu, M., \& Pu, X. (2011). Government regulation on food security-from the view of enterprises and consumers. Contemporary Economic Research, 11, 84-88.

Milgrom, P., \& Roberts, J. (1986). Price and Advertising Signals of Product Quality. Journal of Political Economy, 94(4), 796-821. http://dx.doi.org/10.1086/261408

Nelson, P. (1970). Information and Consumer Behavior. Journal of Political Economy, 78(2), 311-329. http://dx.doi.org/10.1086/259630

Nelson, P. (1974). Advertising as Information. Journal of Political Economy, 82(4), 729-754. http://dx.doi.org/10.1086/260231

Ross, S. A. (1977). The Determination of Financial Structure: The Incentive Signaling Structure. Bell Journal of Economics, 8(1), 23-40. http://dx.doi.org/10.2307/3003485

Spence, A. M. (1974). Job Market Signaling. The Quarterly Journal of Economics, 87(3), 355-374. http://dx.doi.org/10.2307/1882010

Spence, A. M. (2002). Signaling in Retrospect and the Informational structure of Markets. American Economic Review, 92, 434-459. http://dx.doi.org/10.1257/00028280260136200

Wu, H., \& Zeng, X. (2012). Regulation economics on food security issues in China. Public management (pp. 167-170).

\section{Copyrights}

Copyright for this article is retained by the author(s), with first publication rights granted to the journal.

This is an open-access article distributed under the terms and conditions of the Creative Commons Attribution license (http://creativecommons.org/licenses/by/3.0/). 